\title{
Softwares Educacionais e a Educação Especial: Refletindo sobre Aspectos Pedagógicos
}

Claudete Morellato - Prefeitura de Canoas - claudete.morellato@terra.com.br

Maria Cristina Torres Felippim - Colégio Espírito Santo - criskika15@hotmail.com

Liliana Maria Passerino - Centro Universitário Feevale - liliana@feevale.br

Marlise Geller - Universidade Luterana do Brasil - marlise@ ulbra.tche.br

\section{Resumo:}

A proposta para o uso de software educacional, numa perspectiva de aprendizagem, desenvolve-se a partir da utilização da informática educativa considerando questões como: adequação dos conteúdos à realidade do educando, aplicação de novas metodologias que incentivem a participação ativa do aluno no processo de aprendizagem e redefinição dos objetivos a fim de ampliar o desenvolvimento do indivíduo para a sua inserção na sociedade moderna.

Através de planejamento, o uso da informática e de softwares educacionais pode apresentar resultados significativos no processo de construção de conhecimento, proporcionando condições para o desenvolvimento cognitivo e visando a autonomia. Para ir além da utilização do computador como máquina de ensinar, é preciso considerar aspectos pedagógicos e sociais na utilização da informática na aprendizagem. Este artigo analisa como podem ser utilizados os softwares educacionais, em uma perspectiva pedagógica, visando a construção da aprendizagem na educação, e principalmente na educação especial.

Palavras-chave: Software educacional, Construtivismo, Informática na Educação Especial.

\section{Educational Software and Special Education: Thinking about Pedagogical Aspects}

\begin{abstract}
:
The proposal for the use of educational software in a learning perspective develops from the use of educational informatics considering questions as: adaptation of contents to the reality of the student, application of new methodologies that encourage the active participation of the student in the learning process and redefinition of the objectives in order to broaden the formation of the individual to the insertion in the modern society. Through planning, the use of educational informatics and software can bring meaningful results in the process of knowledge building, giving conditions for the cognitive development aiming at autonomy. In order to go beyond the use of computers as teaching machines, it is necessary to consider the pedagogical and social aspects of the use of informatics in learning. So we analyze how the educational software is used, in a pedagogical perspective, aiming at the construct of learning in education, and specially in Special Education.
\end{abstract}

Key-Words: Educational Software, Constructivism, Informatics for Special Education. 


\section{Introdução}

A informática na educação é uma ferramenta importante no processo de aprendizagem. Ferramenta essa que passou por diversas transformações desde o seu surgimento no Brasil. Em meio a tantos projetos e programas desenvolvidos na área nas três últimas décadas, a informática está cada dia mais presente nas escolas, devendo ser mediada por profissionais capacitados e com objetivos claros.

A informática na educação tem assumido diversos significados dependendo da visão educacional e da condição pedagógica em que o computador é utilizado. Para Valente (2001), a informática na educação enfatiza a necessidade do professor ter o conhecimento das potencialidades educacionais do computador para assim poder mesclar atividades de ensino e aprendizagem informatizadas e não informatizadas. E os objetivos, segundo Passerino (2001), devem permitir ao aluno construir significados e representações de forma coletiva e individual, assim, a informática passa a ser utilizada como ferramenta para construção dos conhecimentos, independente do contexto escolar em que está inserida.

Para que a informática possa ser utilizada na aprendizagem, não basta instalar máquinas em seu ambiente, é de suma importância que a escola reflita sobre como o uso dos computadores pode promover situações significativas de aprendizagem.

É certo que a escola é uma instituição que há cinco mil anos se baseia no falar / ditar do mestre, na escrita manuscrita do aluno e, há quatro séculos, em um uso moderado da impressão. Uma verdadeira integração da informática supõe o abandono de um hábito antropológico mais que milenar o que não pode ser feito em alguns anos. (LEVY, 1993, p. 34)

Neste contexto, a utilização do computador como ferramenta educacional, é visto como um instrumento com o qual o sujeito desenvolve, executa algo, ocorrendo assim, o aprendizado através da resolução de problemas e da comunicação, propiciando uma educação centrada na aprendizagem.

As possibilidades do uso do computador como ferramenta educacional estão crescendo e os limites dessa expansão são desconhecidos. Cada dia surge novas maneiras de usar o computador como recurso para enriquecer e favorecer o processo de aprendizagem (VALENTE, 1998, p. 18)

Assim, segundo Felippin (2004), o uso da informática na educação tem como objetivo promover a aprendizagem do aluno, ajudando na construção do processo de conceituação e no desenvolvimento de habilidades importantes para que ele participe da sociedade do conhecimento. Esse uso é efetivado através dos softwares educacionais capazes de tornar a prática do educador e do educando algo prazeroso.

\section{Softwares Educacionais}

Com certeza um dos usos mais freqüentes da informática na escola é através dos softwares educacionais. Consideramos software educacional o conjunto de recursos informáticos projetados com a intenção de serem usados em contexto de aprendizagem. 
Neste sentido a escolha do software, deve favorecer tanto a aprendizagem individual, quanto à coletiva, possibilitando a colaboração entre os educandos e educadores.

Apesar de existirem inúmeros de programas definidos como educacionais, a falta de parâmetros para orientar professores na aplicação pedagógica destes recursos é grande. Por isso compreendemos que a escolha do software educacional é uma tarefa complexa que envolve diversos fatores, entre eles os pedagógicos de integração curricular e de uso em aspectos específicos como na educação especial. Assim tal escolha e a forma de utilização dos softwares educacionais devem estar embasadas em uma proposta significativa, objetivando-se a construção e a organização do raciocínio para que possa refletir sobre a aprendizagem do indivíduo.

Constantemente são lançados novos softwares que prometem auxiliar no desenvolvimento cognitivo do aluno e conseqüentemente contribuir na efetivação do processo de ensino e aprendizagem. Segundo Papert (1985), uma das dificuldades que os educadores enfrentam é selecionar, entre os diferentes softwares disponíveis no mercado, aqueles que serão mais adequados para os seus objetivos educacionais e para os seus alunos.

Portanto, se o uso dos softwares educacionais trouxer junto consigo uma proposta planejada, a informática torna-se um meio, um instrumento, e não um fim em si mesma.

Diante uma proposta embasada de tal forma, concordamos com Weiss \& Crus (2001, p. 10) “... o importante não é mais o conjunto de conhecimentos, mas o que esses conhecimentos possibilitam como degraus para novas aprendizagens", pois ao utilizarmos a informática como ferramenta no processo de aprendizagem, podemos promover o surgimento de hipóteses e conflitos que favoreçam a construção de novos conhecimentos.

A construção de situações que partem da solução de problemas, e principalmente do processo que gera essas soluções (processo de conflito), favorecem a reflexão e o aprendizado em seus aspectos pedagógicos. Uma das formas de auxiliar no desenvolvimento das estruturas do pensamento é levando em conta que o sujeito é um ser pensante e que aprende pela experimentação através de projetos educacionais. $\mathrm{O}$ sujeito aprende fazendo, agindo, experimentando, assim a informática atua como mediadora desse aprendizado oferecendo a possibilidade de desenvolver conhecimentos significativos.

Segundo Felippin (2004), para que essa construção ocorra é necessário mais do que um ambiente centrado no aluno é necessário que o aluno seja construtor desse ambiente, considerando que ele é capaz de criar novas situações favorecendo assim, a descoberta do conhecimento.

De acordo com Weiss \& Crus (2001), o que ocorre é que diante do computador, a rotina da sala de aula pode ser esquecida pela criança. Desta forma, esta criança acaba por revelar conhecimentos que constrói e que já havia construído, tornando-se um ser em busca de auto-conhecimento e melhor relacionamento com o outro.

O software em um contexto geral, promove atitudes inovadoras e importantes tanto no processo de aprendizagem do sujeito que o utiliza, quanto do mediador V. $4 \mathrm{~N}^{\circ} 1$, Julho, 2006 
(educador) que favorece o seu uso. Assim para que ocorram as situações de aprendizagem é necessário planejamento por parte do educador, pois a utilização de softwares em áreas específicas transcorre da mesma forma, sustentando a idéia de que é necessário conhecer, e planejar antes de aplicar.

\section{Conhecendo Softwares Educacionais}

Os diferentes tipos de softwares são classificados por categorias, onde é possível fazer uma distinção entre a sua utilização, as funções e os fundamentos educacionais que representam para que as possíveis aplicações respeitem os aspectos pedagógicos e os objetivos que se deseja alcançar na aprendizagem.

Existem diversas formas de classificar os softwares educacionais como em Felippin (2004), Valente (1998) e Passerino (2001), a figura 1 representa os softwares classificados como recurso didático levando em consideração que todos possuem uma relação com a aprendizagem.

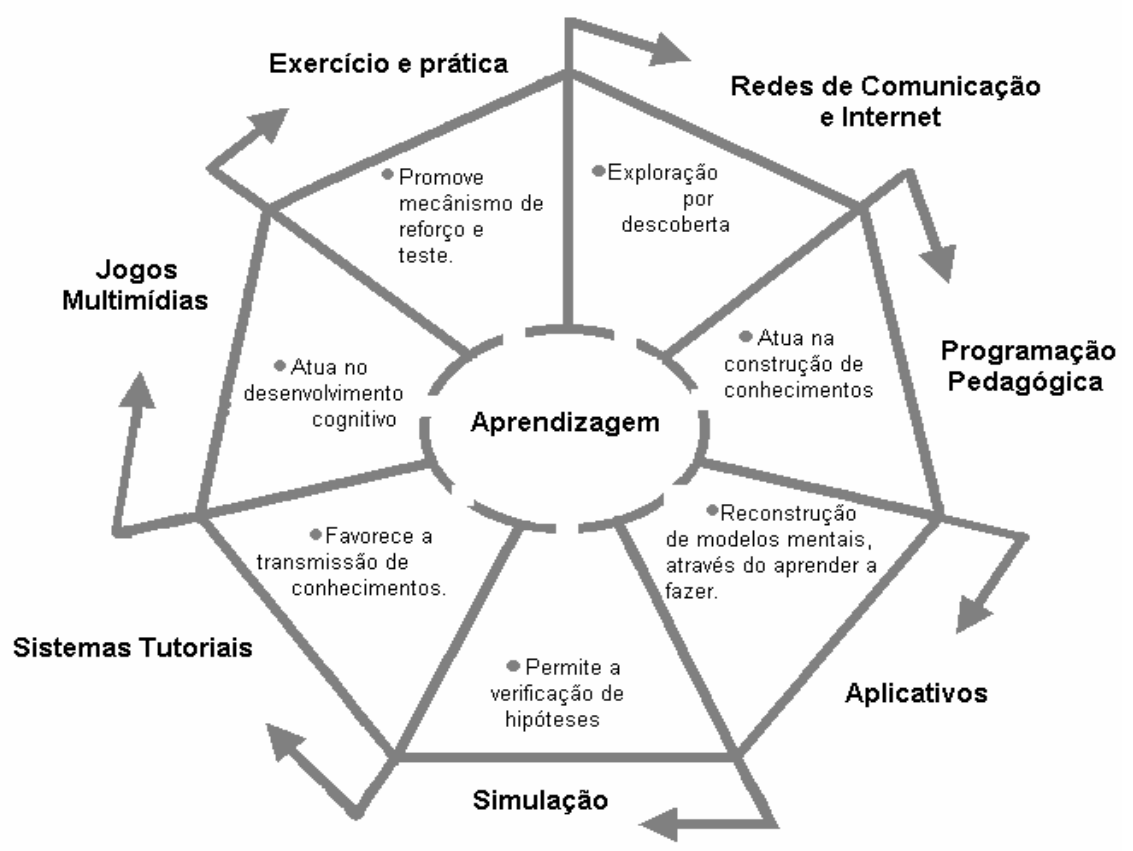

Figura 1: Classificação dos softwares e atuação no processo de aprendizagem - (Fonte: Felippin, 2004)

Os softwares educacionais têm assumido diversos significados dependendo da visão educacional e da condição pedagógica em que o computador é utilizado. Para Valente (2001), a informática na educação enfatiza a necessidade do professor ter conhecimento das potencialidades educacionais do computador para assim poder mesclar atividades de ensino e aprendizagem informatizadas e não informatizadas.

Todos os softwares podem ser usados numa perspectiva educacional. Nesse sentido, é fundamental que o educador, que irá mediar o uso do software tenha coerência quanto à sua escolha, criando situações e permitindo que as ações dos alunos recriem essas situações sendo capazes de construir conhecimentos. Para Passerino (2001, p.174) "a aprendizagem com tecnologia, se embasa nas teorias construtivistas, 
nas quais o conhecimento é construído pelo sujeito e não transmitido". A construção parte de um processo ativo, engajado em atividades cognitivas que estão inseridas num contexto complexo. Assim, os softwares são vistos como complemento nos processos de conhecimentos, facilitando a aprendizagem em diferentes situações de ensino, auxiliando o sujeito na leitura e na escrita.

Mas, para criar um ambiente de aprendizagem centrado no aluno como agente ativo é necessário considerar que o ambiente deve prever não apenas apresentação de situações de aprendizagem, mas também, permitir ao aluno a criação de novas situações, lembrando que essa resolução pode ser social e não apenas individual. (Passerino, 2001)

Lévy (1993), destaca que da mesma forma em que a criatividade inventiva do homem, gera novas ferramentas tecnológicas e modifica constantemente os instrumentos que inventa, existe um efeito inverso: a tecnologia modifica a expressão criativa do homem, transformando a sua maneira de adquirir conhecimento $\mathrm{e}$ interferindo na efetivação da aprendizagem.

Passerino acrescenta que:

(...) a utilização do computador para a criação de ambientes de aprendizagem é uma das tantas possibilidades de uso desta ferramenta na educação. Mas, para criar ambiente de aprendizagem centrado no aluno como agente ativo é necessário considerar que o ambiente deve prever não apenas apresentação de situações de aprendizagem, mas, também, permitir ao aluno a criação de novas situações, lembrando que essa resolução pode ser social e não apenas individual. (2001, p. 176)

É importante destacar que isso só será possível a partir do momento que o computador for efetivamente utilizado como instrumento no processo de ensino e aprendizagem, e se for inserido num contexto de atividades que desafiem os alunos a crescerem, construindo seu conhecimento e estimulando para que não continuem assumindo posições de passividade diante da realidade e de problemas vivenciados.

\section{A Informática na Educação Especial}

Atualmente, em grande parte dos espaços de atendimento a alunos com necessidades educacionais especiais, programas alicerçados na informática se fazem presentes, visando motivar e valorizar o "saber" destes alunos que por muitos anos foi segregado.

A Informática na Educação Especial favorece trabalhar na perspectiva de pensar e repensar a prática pedagógica, de modo a torná-la eficaz no propósito de possibilitar a aprendizagem promovendo uma ruptura de algumas práticas que concebem os alunos como iguais e não como sujeitos sócio-culturais com experiências e necessidades diversas.

Ele se torna o caderno eletrônico para o deficiente físico, um meio que o surdo pode usar para estabelecer relações entre o fazer e os conceitos utilizados nestas ações, um instrumento que integra diferentes representações de um determinado conhecimento para o deficiente visual, o medidor de interação da criança autista e o mundo, um objeto de desafios para a criança deficiente mental e, o recurso com 
a qual a criança carente pode realizar-se e participar efetivamente de atividades socioculturais significativas. (VALENTE, 2001, p.30)

Tajra (2001), destaca que a maioria dos softwares utilizados em pessoas com necessidades educativas especiais são softwares abertos (como os classificados em Linguagem de Programação). Na realidade são poucos os softwares voltados especificamente para estes usuários, uma vez que qualquer software que estimule a percepção auditiva e perceptiva e o desenvolvimento psicomotor, pode ser utilizado com estes alunos.

Destaca também que o grande "trunfo" do computador é sua característica interativa com o meio. Por meio dele, é possível integrar diversas mídias e demais recursos tecnológicos, desde o rádio, a televisão, os vídeos, as filmadoras; portanto, um recurso perfeito para trabalhar sons, cores, figuras e imagens, sendo bem vindo no ambiente educacional. A sua utilização, com alunos com necessidades educativas especiais, auxilia na aquisição de conhecimentos pelo aspecto lúdico oferecido.

Assim o professor deverá identificar quais os déficits cognitivos que a criança possui e suas dificuldades no processo de aprendizagem, e a partir destes conhecimentos desenvolver uma proposta pedagógica onde o uso do computador será um recurso pedagógico utilizado, objetivando o interesse do aluno pela aprendizagem dos conteúdos acadêmicos e as habilidades mentais necessárias para a realização das atividades propostas.

Morellato (2004) destaca que softwares do tipo jogos, neste caso, desempenham uma dupla função: a lúdica e a educativa de maneira atraente e motivadora, pois os mesmos permitem manifestar um grande número de interações como tomada de decisões, escolha de estratégias e respeito às regras impostas, além de permitir representações simbólicas e desenvolvimento do imaginário do aluno.

Ainda acrescenta que, alunos com necessidades educacionais especiais, interagem com o computador de forma adequada, e que o fascínio pela máquina funciona como agente motivador, por isso aprendizagem acontece informalmente e de maneira prazerosa. Conforme pode constatar em sua pesquisa que tratava da construção de habilidades para resolução de problemas matemáticos em um sujeito com necessidades educacionais especiais com suporte da Informática na Educação e que se propunha identificar como a informática, através de softwares educacionais, pode auxiliar no desenvolvimento de habilidades para resolução de problemas matemáticos em um sujeito com deficiência mental.

\section{Explorando Softwares Educacionais: Uma Prática Contextualizada}

Quando se trata das possibilidades do uso de softwares educacionais, os mais utilizados são os jogos multimídias, a programação pedagógica e em alguns casos a Internet. Ou seja, existe uma diversidade de softwares que podem ser utilizados no processo aprendizagem, desde que sejam considerados os objetivos pedagógicos.

Para que o professor possa propor boas situações de aprendizagem utilizando a informática é fundamental conhecer os softwares que pretende utilizar para problematizar conteúdos curriculares. Por isso, cada software deve ser explorado pelos 
professores com o objetivo de identificar suas potencialidades pedagógicas. (PCN, 1998, p.151)

Um dos primeiros softwares de programação utilizados em projetos educacionais foi a linguagem LOGO. Sendo uma linguagem de programação desenvolvida para crianças, adapta-se às escolas que trabalham em ambientes construtivistas e, também é recomendado para trabalhar com crianças que possuem dificuldades de aprendizagem.

Sua característica básica é a forma de comunicação que se aproxima muito do modo como se estrutura o pensamento da criança. É através do erro, com sua posterior análise e a elaboração de hipóteses válidas, para buscar possíveis soluções, que a criança formula o aprendizado.

A linguagem LOGO foi desenvolvida na década de 60 por Seymour Papert e, desde então vem sendo utilizada. Consiste em programar uma tartaruga para que realize os procedimentos desejados. $\mathrm{O}$ aspecto lúdico do ambiente estimula a criança, pois ao mesmo tempo em que "ensina" a tartaruga, também está aprendendo. Neste processo de ensinar, a criança reflete sobre os seus próprios processos para poder descrever o que realmente deseja que o computador execute.

Outro tipo de software, que merece destaque, são os softwares para a construção de histórias em quadrinhos. Em pesquisas realizadas por Bottazini (1999), Cisne (2000) e Moraes (2000) com o objetivo de auxiliar a escrita e a leitura na fase de alfabetização, através da mediação dos softwares educacionais, as autoras utilizam os softwares de construção de histórias em quadrinhos, uma vez que esses softwares possibilitam ao educando construir, refletir e organizar o pensamento, pois o aspecto lúdico que esses apresentam aguçam a curiosidade da criança, ocupando assim um espaço relevante, principalmente no processo de escrita e leitura.

A fim de romper com a forma tradicional de aprendizagem, Felippin (2004), utiliza em sua pesquisa o software de história em quadrinhos HagáQuê ${ }^{1}$ para formular situações de aprendizagem capazes de auxiliar na construção de conhecimentos, da língua escrita e da leitura, apóia-se na teoria de Ferreiro (1995) e sustenta a idéia de que "o sujeito aprende fazendo, agindo, experimentando, e que assim a informática atua como mediadora desse aprendizado oferecendo a possibilidade de desenvolver conhecimentos significativos, unindo as experiências do aluno as atividades realizadas em sala de aula". Podendo-se constatar que ocorre uma evolução na construção da escrita e da leitura, quando existe uma proposta de trabalho contextualizada de forma construtiva.

Diante da utilização de softwares educacionais, o aluno pode tornar-se mais autônomo, assim consideramos que softwares como jogos digitais, que atuam no desenvolvimento cognitivo quando é proposto o desafio, podem tornar-se uma estratégia motivadora, envolvendo o aluno em situações que promovem a sua autonomia. Tais softwares possuem ainda, a função de auxiliar o aluno para a convivência social, pois, permitem vivenciar de maneira natural situações norteadas por regras, desenvolvendo habilidades de resolução de problemas e tomada de decisões.

\begin{tabular}{l}
\hline $\begin{array}{c}\text { Software elaborado e } \\
\text { http://www.nied.unicamp.br/ hagaque/. }\end{array}$ \\
V. $4 \mathrm{~N}^{\mathrm{o}}$ 1, Julho, 2006
\end{tabular}


Aprende-se também a cooperar, elaborar estratégias e projetar conseqüências de longo ou curto prazo em um determinado cenário.

Mais uma vez o caráter lúdico constitui uma forma divertida de aprender, podendo ser usado para ensinar conceitos que na prática são difíceis de serem compreendidos por não existirem aplicações perceptíveis de forma imediata.

Segundo Passerino (1998), os jogos mantém uma relação estreita com construção do conhecimento e possui influência como elemento motivador no processo de ensino e aprendizagem. Já Valente (1998), ressalta que em relação a multimídia e internet, devem ser destacados os seguintes aspectos: uso de uma multimídia já pronta e o uso de sistemas de autoria para o aluno desenvolver sua multimídia. A multimídia pronta é semelhante ao tutorial, apesar de oferecer muitas possibilidades de combinações com textos, imagens, som, a ação do aluno se resume em escolher opções oferecidas pelo software. Valente acrescenta que:

Ele não está descrevendo o que pensa, mas está decidindo entre várias possibilidades oferecidas. Uma vez escolhida a seleção, o computador apresenta a informação disponível e o aprendiz pode refletir sobre a mesma. Às vezes o software pode oferecer também ao aprendiz, oportunidade de selecionar outras opções e navegar entre elas. Essa idéia pode manter o aprendiz ocupado por um certo tempo e não oferecer-lhe oportunidade de compreender e aplicar de modo significativo às informações selecionadas. (1998, p.102)

Dessa forma, o uso de multimídia e ferramentas da Internet podem propiciar atividades que auxiliam o aluno a adquirir informações, mas não a compreender ou construir conhecimentos com a informação obtida. Tornando-se necessária à intervenção do professor para que o conhecimento seja construído.

Passerino, referindo-se a Internet, ressalta que:

"talvez seja o uso que mais irá revolucionar o processo de ensino e aprendizagem. Todas as ferramentas anteriores foram desenvolvidas e pensadas para serem usadas de maneira individual, no binômio usuário-computador. Com as redes de comunicação, e em especial a Internet (com todos os seus serviços: e-mail, listas, fóruns, páginas WWW, entre outros) o binômio usuário computador foi substituído pelo trinômio usuário-computador-usuário...” (2001, p.179)

Podemos citar a experiência do ensino a distância via Internet, através do Projeto de Informática na Educação Especial (PROINESP) que possibilita a formação de professores a um só tempo, habilitando-os a integrar os conhecimentos construídos ao longo desta formação, simultaneamente ao aprendizado de seus alunos, agilizando o processo de inclusão com as tecnologias da comunicação e da informação e, conseqüentemente, unindo educador e educando em novas vivências.

\section{Considerações Finais}

Sabendo que, a escola não pode deixar de incorporar as novas transformações, cabe ao educador a responsabilidade de buscar e intervir para sistematizar as diversas ferramentas disponíveis, integrando-as como recurso pedagógico a fim de criar condições cabíveis de aprendizagem. 
Por isso, deverá ter claro qual o paradigma implícito em sua proposta de utilização do computador para então definir sua prática. Se seu olhar está voltado a possibilitar uma interação do aluno com recursos tecnológicos, visando preparar o aluno para o futuro mercado de trabalho, a importância será dada apenas aos conceitos de informática, sem a preocupação de interatividade com a proposta pedagógica da escola.

A interação aluno-computador necessita da intervenção de um profissional que saiba o significado do processo de aprendizagem baseado na construção do conhecimento. Só assim poderá intervir apropriadamente de modo que auxilie seu aluno. (VALENTE, 2001, p. 35)

Morellato (2004) destaca que estratégias pedagógicas devem ser bem estruturadas visando motivar o aluno para a aprendizagem, desenvolver sua autonomia e contribuir no desenvolvimento positivo de sua auto-imagem.

Portanto, trabalhar na perspectiva tecnológica, inserindo a possibilidade de diferentes ambientes educacionais, permite ao aluno produzir novas formas de construir o conhecimento, favorecendo a aprendizagem individual e coletiva, desenvolvendo assim a colaboração entre os educandos.

Neste contexto o professor deverá evidenciar através da utilização de softwares educacionais, intervenções pedagógicas que contribuam para a efetivação do processo de ensino e aprendizagem visando à construção integrada do conhecimento, desenvolvendo no aluno o pensamento lógico e o espírito investigativo através da resolução de situações-problemas, que servirão para compreender e transformar sua realidade. Assim, acreditamos que o aluno, frente aos recursos que a tecnologia oferece, irá descobrindo formas de adequar a busca de informações com a construção de seu conhecimento, estimulando o desenvolvimento de habilidades e valores que contribuirão na sua formação como sujeito histórico-social e cultural.

Os softwares educacionais quando bem contextualizados, podem tornar-se aliados no processo de ensino e aprendizagem, pois, desempenham uma dupla função: a lúdica e a didática de maneira criativa, motivadora e prazerosa. Espera-se que o educador, em seu papel de mediador, desenvolva o seu trabalho de uma maneira significativa em relação à aprendizagem do educando.

\section{Referências}

PCN - BRASIL, Secretaria de Educação Fundamental. Parâmetros Curriculares Nacionais PCN, $3^{\circ}$ e $4^{\circ}$ Ciclos do Ensino Fundamental. Português. Secretaria de Educação Fundamental, Brasília: MEC, SEF, 1998.

BOTTAZINI, Lara Marines. A contribuição dos softwares no processo de alfabetização. Florianópolis. Universidade Federal de Santa Catarina. Dissertação (Engenharia e Produção de Sistemas), 2001.

CISNE, Margareth Feiten, Educação Infantil e os softwares educacionais: Abrindo caminhos para exploração de critérios pedagógicos. Florianópolis: Universidade Federal de Santa Catarina. Dissertação (Engenharia de produção e sistemas), 1999.

FELIPPIN, M. Cristina Torres. A construção da escrita e leitura: aplicações de situações de aprendizagem envolvendo material concreto e softwares educativos em um processo de alfabetização. Canoas: Universidade luterana do Brasil (Monografia de Especialização em Informática na Educação), 2004.

LEVY, P. Tecnologias da Inteligência. O futuro do pensamento na era da informática. Rio de Janeiro: 341993.

V. $4 \mathrm{~N}^{\mathrm{o}} 1$, Julho, 2006 
MORAES, Regina Aparecida de. Recursos tecnológicos e intervenções pedagógicas significativas no ensino da ortografia. Florianópolis: Universidade Federal de Santa Catarina. Dissertação (Engenharia de produção), 2000.

MORELLATO, Claudete. A construção de habilidades para a resolução de problemas matemáticos em um sujeito com necessidades especiais educacionais alicerçado na informática da educação. Canoas. Universidade luterana do Brasil. (Monografia de Especialização em Informática na Educação), 2004.

PAPERT, Seymour. Logo: Computadores e Educação. São Paulo: Brasiliense,1985.

PASSERINO, Liliana. Avaliação de Jogos Educacionais Computadorizados. In: III Taller Internacional de Software Educativo, TISE 98, 2 a 6 de dezembro de 1998, em Santiago do Chile. Disponível em http://www.c5.cl/tise98/trabajos/jogosed

PASSERINO, Liliana Maria. Informática na Educação Infantil: Perspectivas e possibilidades. In: ROMAN, Eurilda Dias; STEYER, Vivian Edite. (Org.). A Criança de 0 a 6 anos e a Educação Infantil: um retrato multifacetado. Canoas, ULBRA, 2001, p. 169-181.

TAJRA, Samya. Informática na Educação: Novas Ferramentas Pedagógicas para o Professor da Atualidade. 3.ed. São Paulo: Érica, 2001.

VALENTE, J. A. Computadores e conhecimento: repensando a educação. [s.ed.] Campinas: Gráfica Central da UNICAMP, 1998.

VALENTE, José Armando (org.). Aprendendo para a vida: os computadores na sala de aula. São Paulo: Cortes, 2001.

VALENTE, J. A. (s.d.) O uso inteligente do computador na educação. Disponível em: < http://www.diretoriadeitapevi.com.br/texto2.html > Acesso em 05.05.2004.

WEISS, Alba M. L. e CRUS, Mara Lúcia R. A informática e os problemas escolares de aprendizagem. 3. ed. Rio de Janeiro: DpeA, 2001. 